\title{
Control of a Power Generation System Based on a Dual Star Induction Generator
}

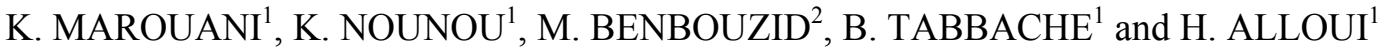 \\ ${ }^{1}$ Laboratoire Commande des Machines \\ Ecole Militaire Polytechnique \\ Bordj El-Bahri-16046, Algiers, Algeria \\ Phone/Fax number:+00213218632 04, e-mail: marouani_khoudir@yahoo.fr \\ ${ }^{2}$ University of Brest, EA 4325, LBMS, Rue de Kergoat, CS 93837, 29238 Brest Cedex 03, France \\ Phone/Fax number:+0033 2980166 43, e-mail: mohamed.Benbouzid@univ-brest.fr
}

\begin{abstract}
This paper presents a control scheme of a power generation system based on a dual star squirrel-cage induction machine operating as an induction generator. The operating mode based on an excitation control scheme is chosen to ensure a controlled magnitude and frequency of the generator output voltage. Some preliminary simulation and experimental test results, carried out on a prototype of dual star induction machine operating as generator and supplying various loads under different conditions, are presented and discussed.
\end{abstract}

\section{Key words}

Six-phase induction machine, Self-excited induction generators, Magnetic saturation, Renewable energy.

\section{Introduction}

Induction machines are widely used in various areas and vast range of energy conversion applications. Since, the benefits of induction machines are well known and amply demonstrated, currently, they are faced to mutations towards new applications as renewable energy generation. Nevertheless, the control principle is difficult and complicated because the induction generator can only be fed through the stator side which constitutes the excitation and generation part at the same time. Thus, at present induction generators are particularly used in small and isolated power plants based on wind turbine or hydroelectric generators [1]-[3]. However, the power electronics developments in conjunction with control theories have encouraged researchers to conduct substantial works and to bring attention to the opportunity of emergent applications of induction generators. Among the new challenges, multiphase induction machines are considered as promising solution for renewable energy applications [4]. Accordingly, apart the fact that high phase order drives possess some advantageous features as compared to conventional three-phase drives, such as reducing the amplitude and increasing the frequency of torque pulsation, reducing the rotor harmonic currents, power segmentation, high reliability and increased power [5], the number of phases can be used as an additional degree of freedom to make this kind of machines suitable for renewable energy applications.

The main objective of this paper is to present some preliminary test results carried out on a dual star induction machine operating as an induction generator and supplying various loads under different conditions. Hence, this paper presents an excitation control scheme of the dual star induction generator (DSIG) to ensure a controlled magnitude and frequency of the output voltage, as shown in Fig. 2. This control scheme is presented to overcome the problems encountered in case of the selfexcited induction generator, which is an open-loop operating mode and the generated voltage amplitude and frequency depend on the rotating speed and the size of the excitation capacitors, therefore this operating mode is suitable for loads which are not sensible to voltage and frequency variations [6].

Also, in order to support this study simulation results are presented and validated by some experimental tests, conducted on a $5.5 \mathrm{~kW}$ prototype of dual star squirrel-cage induction machine supplying different electrical loads.

\section{Power Generation System Description}

The energy conversion system consists of a DSIG with stator windings separated into two identical three-phase winding sets. The generator is driven by a prime mover and is feeding static loads. The control scheme of the DSIG ensuring a controlled magnitude and frequency of the output voltage is shown in Fig. 1. So, the first star is connected to a PWM-VSI and used as excitation or control winding $(\mathrm{CW})$ which provides the necessary reactive power, while the second one acts as power winding (PW) connected to the load and meets the active power demand. This system presentation is adopted in order to get a general representation model which can be later used to develop control strategies similar to that of doubly-fed induction generator. So, one three-phase winding set can be used for excitation purpose as control winding, while the second one can be used as power generation winding. 


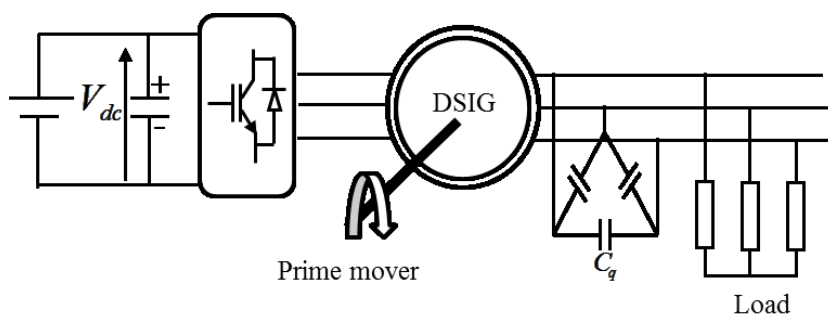

Fig. 1. Control scheme of the DSIG.

\section{Modeling of the DSIG}

The real model of the induction generator is exactly similar to that of an induction motor and the only difference lies in placing a minus sign before the current phase symbolizing the generator mode instead of a motor one. Also, the model of the DSIG can be easily pointedout based on that of the six-phase motor, moreover, as the stator winding is separated into two identical three-phase winding sets, the usual Park transform can be applied to each three-phase set separately, adopting the usual simplification assumptions [7]-[9]. Thus, the SPIG model expressed in the synchronous reference frame is decomposed into two main sub-models for the stator side and one sub-model for the rotor side as in a following.

\section{A. Stator Voltage Equations}

The stator voltage sub-models are noted $\left(\mathrm{sd}_{1}-\mathrm{sq}_{1}\right)$ for the first stator winding set and $\left(\mathrm{sd}_{2}-\mathrm{sq}_{2}\right)$ for the second stator winding set, as follows:

$\left\{\begin{array}{l}V_{s d 1}=-R_{s} I_{s d 1}+\frac{d \Phi_{s d 1}}{d t}-\omega_{s} \Phi_{s q 1} \\ V_{s q 1}=-R_{s} I_{s q 1}+\frac{d \Phi_{s q 1}}{d t}+\omega_{s} \Phi_{s d 1}\end{array}\right.$
$\left\{\begin{array}{l}V_{s d 2}=-R_{s} I_{s d 2}+\frac{d \Phi_{s d 2}}{d t}-\omega_{s} \Phi_{s q 2} \\ V_{s q 2}=-R_{s} I_{s q 2}+\frac{d \Phi_{s q 2}}{d t}+\omega_{s} \Phi_{s d 2}\end{array}\right.$

\section{B. Rotor Voltage Equations}

The rotor sub-model is noted (rd-rq) and written as follows:

$\left\{\begin{array}{l}V_{r d}=0=R_{r} I_{r d}+\frac{d \Phi_{r d}}{d t}-\omega_{r} \Phi_{r q} \\ V_{r q}=0=R_{r} I_{r q}+\frac{d \Phi_{r q}}{d t}+\omega_{r} \Phi_{r d}\end{array}\right.$

\section{Stator And Rotor Flux Equations}

Also the transformed stator and rotor flux are presented according to the three sub-models as follows:

$$
\begin{aligned}
& \left\{\begin{array}{l}
\Phi_{s d 1}=-L_{l s} I_{s d 1}+L_{m}\left(-I_{s d 1}-I_{s d 2}+I_{r d}^{\prime}\right) \\
\Phi_{s q 1}=-L_{l s} I_{s q 1}+L_{m}\left(-I_{s q 1}-I_{s q 2}+I_{r q}^{\prime}\right)
\end{array}\right. \\
& \left\{\begin{array}{l}
\Phi_{s d 2}=-L_{l s} I_{s d 2}+L_{m}\left(-I_{s d 1}-I_{s d 2}+I_{r d}^{\prime}\right) \\
\Phi_{s q 2}=-L_{l s} I_{s q 2}+L_{m}\left(-I_{s q 1}-I_{s q 2}+I_{r q}^{\prime}\right)
\end{array}\right.
\end{aligned}
$$

$\left\{\begin{array}{l}\Phi_{r d}^{\prime}=-L_{l r} I_{r d}^{\prime}+L_{m}\left(-I_{s d 1}-I_{s d 2}+I_{r d}^{\prime}\right) \\ \Phi_{r q}^{\prime}=-L_{l r} I_{r d}^{\prime}+L_{m}\left(-I_{s q 1}-I_{s q 2}+I_{r q}^{\prime}\right)\end{array}\right.$

In order to simplify the flux equations, the rotor flux $\Phi_{r}{ }_{r}^{\prime}$ and current $I_{r}^{\prime}$ variables moved to stator side are introduced instead of $\Phi_{r}$ and $I_{r}$ variables. The parameter $L_{m}$ is the magnetizing inductance which expresses the relation between the total magnetizing flux $\phi_{m}$ and current $I_{m}$, as follows:

$L_{m}=\frac{\phi_{m}}{I_{m}}$

The magnetizing current is given by:

$I_{m}=\sqrt{\left(-I_{s d 1}-I_{s d 2}+I_{r d}^{\prime}\right)^{2}+\left(-I_{s q 1}-I_{s q 2}+I_{r q}^{\prime}\right)^{2}}$

The magnetizing inductance $L_{m}$ is a non-linear function of the magnetizing current $I_{m}$ and depends on the saturation level. The magnetizing inductance constitutes an important parameter for the generator model and it can be determined using the machine real magnetizing curve. So, its analytical expression can be written as follows [6], [10].

$L_{m}=\frac{c_{1} I_{m}^{c_{2}}+c_{6}}{c_{3} I_{m}^{c_{4}}+c_{5}}$

Where: $c_{1}, c_{2}, c_{3}, c_{4}, c_{5}$, and $c_{6}$ are constant parameters given in Appendix.

The complete model of the DSIG is established according to a particular scheme considering the stator winding as two three-phase sets sharing the same magnetic circuit. The next section presents the simulation results of the excitation control scheme of the SPIG, supplying various loads under different conditions, to ensure a controlled magnitude and frequency of the output voltage (Fig. 1), followed by some preliminary experimental tests to validate the developed model.

\section{Excitation Control System Description}

Figure 2 presents the control principle of the DSIG where the excitation VSI is feeding the CW with a battery source or a capacitor. The control of the VSI is based on a simple technique using the desired peak value of the PW phase voltage as a reference which is compared to the measured value and regulated with a PI controller to ensure the voltage magnitude regulation. Also, the output voltage frequency can be imposed using an input modulation signal multiplied by the voltage magnitude at the PI output, in order to form the VSI reference signals which constitute the PWM bloc input [13]. 


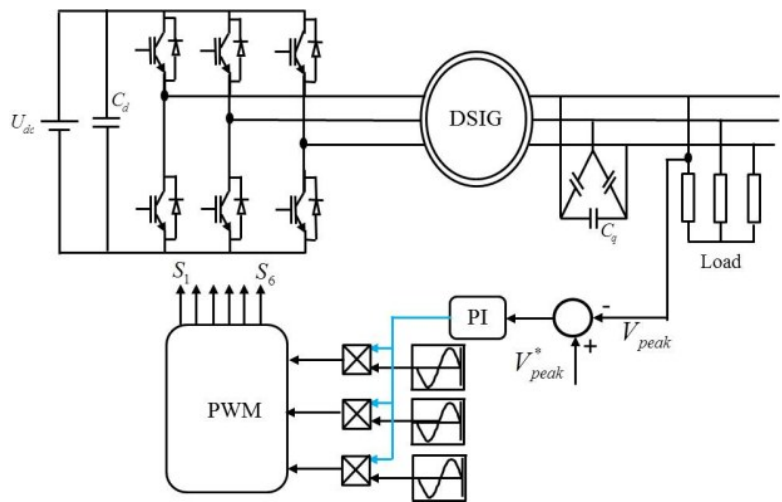

Fig. 2. Detailed control scheme of the DSIG.

\section{Excitation Control System Description}

Simulation of the whole model of the DSIG (Fig.2) is performed for different operating cases under various conditions. Hence, the DSIG voltage and current wave forms at the terminal of the stator windings are firstly presented at no-load and then for a resistive $(R)$ load. Also, the influence of mechanical speed variations on the voltage generation is shown.

So, Fig. 3 shows the peak value of the PW phase voltage and its reference at no-load and then for a resistive $(R)$ load of $100 \Omega$ at $\mathrm{t}=0.7 \mathrm{sec}$. Also, the influence of mechanical speed variations from $1000 \mathrm{rpm}$ to $715 \mathrm{rpm}$ at $\mathrm{t}=1 \mathrm{sec}$ and then to $1098 \mathrm{rpm}$ at $\mathrm{t}=1.5 \mathrm{sec}$ are shown. It can be observed that after each variation, the PW phase voltage returns to its reference value by the mean of the PI controller. Moreover, Fig. 4 shows the voltage wave forms at the terminal of the $\mathrm{PW}$, at the same previous conditions, and confirms that the voltage magnitude $(220 \mathrm{~V})$ and frequency $(50 \mathrm{~Hz})$ are kept constant and balanced before as well as after load and speed variations.

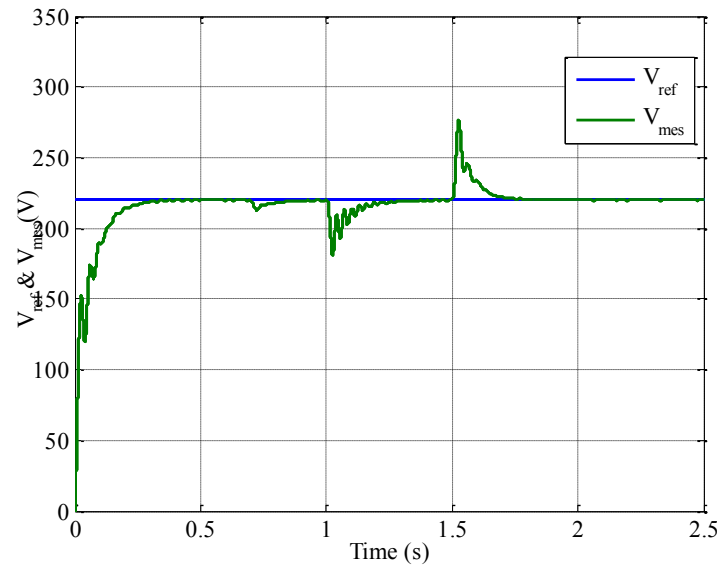

Fig. 3. The peak value of the PW phase voltage and its reference.

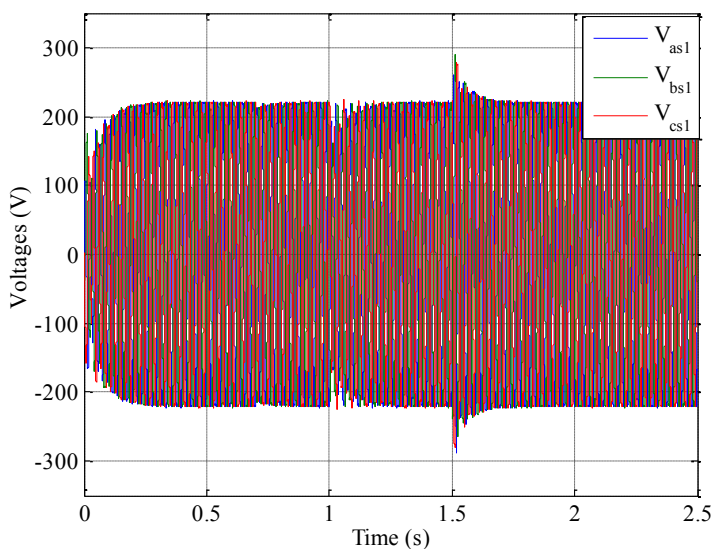

(a) PW terminal voltage before and after load and speed variations.

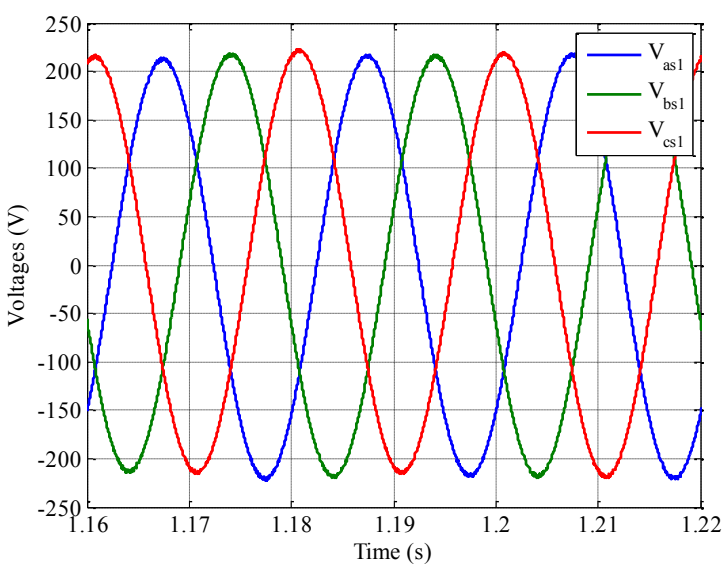

(b) Zoom on the PW voltage after a speed variation

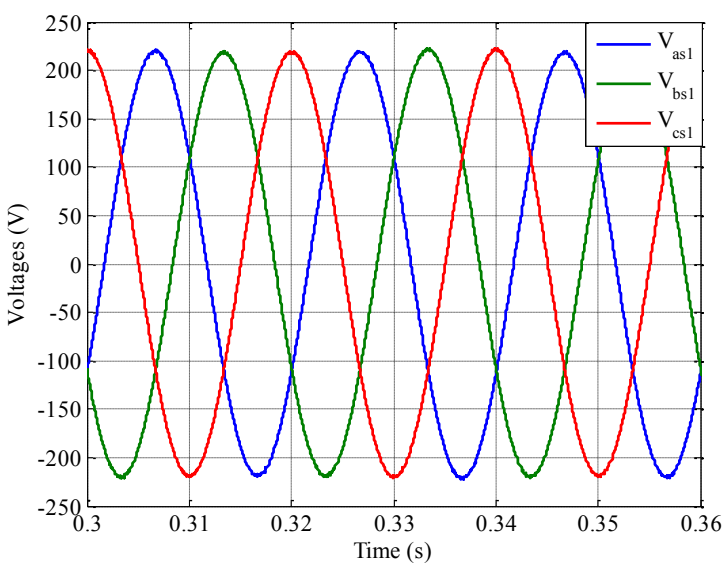

(c) Zoom on the PW voltage at no load

Fig. 4. The voltage wave forms at the PW terminal.

Figure 5 shows simulated load voltage (divided by 50) and current waveforms of the PW feeding a resistive load of $100 \Omega$. It can be revealed that the CW inverter injected harmonics which can be induced in the load are minimal due to the rotor action. 


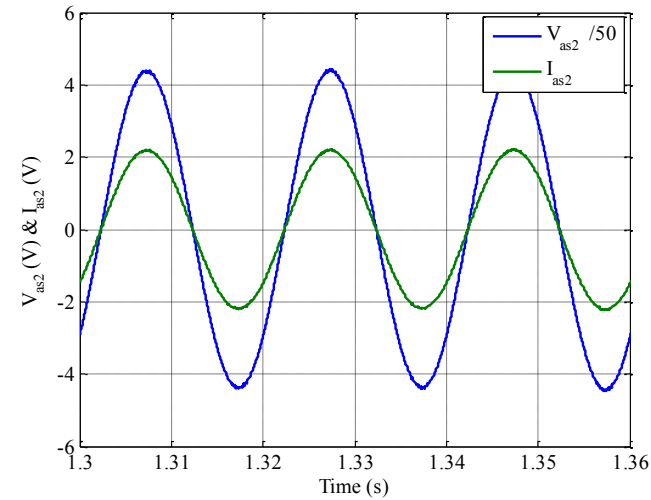

Fig. 5. Voltage and current waveforms of the PW with a load of $100 \Omega$.

Figure 6 shows that the CW voltage (divided by 30) and current components are in quadrature. As the $\mathrm{CW}$ is used for excitation purpose and only provides the necessary reactive power, it is shown that under well-defined conditions they are in quadrature (reactive current). Also, Fig. 7 shows the active and reactive power curves at the $\mathrm{CW}$ side, and confirms that the inverter provides only the reactive power.

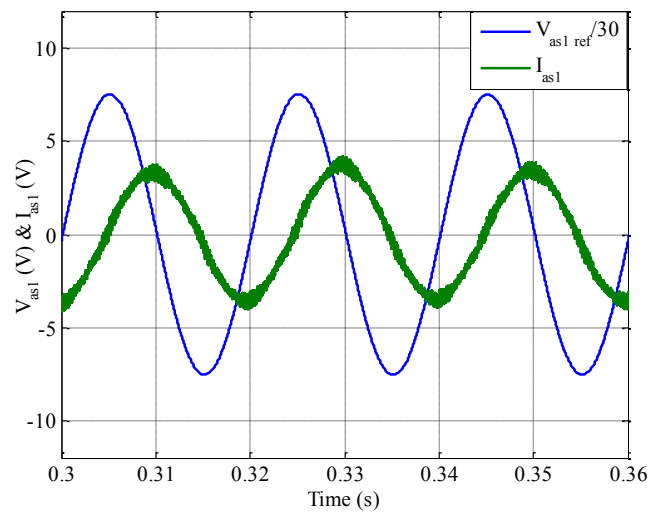

Fig. 6. $\mathrm{CW}$ voltage and current components.

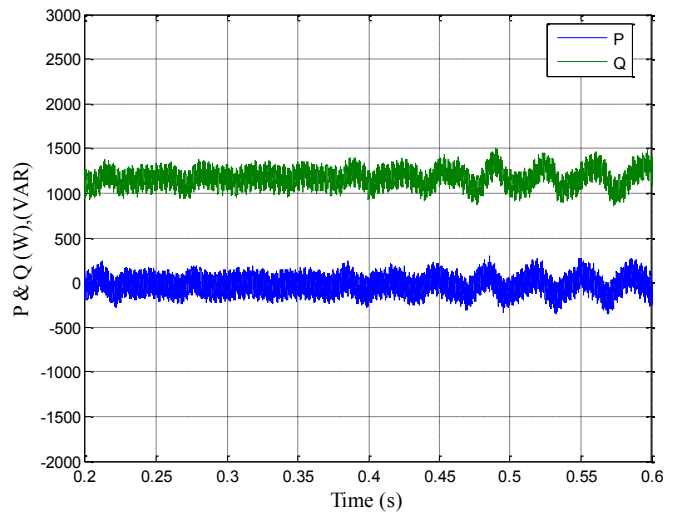

Fig. 7. CW active and reactive powers.

\section{Experimental Results Of DSIG Control}

Experiments are carried-out on an experimental test bench to check the simulation results. The laboratory test bench consists of a dual star induction machine (DSIM: $5.5 \mathrm{~kW}$, 6 poles) configurable as symmetrical or asymmetrical sixphase induction machine operating as generator and coupled to a DC motor used as prime mover as shown in
Fig. 8 [12]. The experimental tests on the SPIG are done for the same operating cases and conditions as well as the simulation tests presented above.

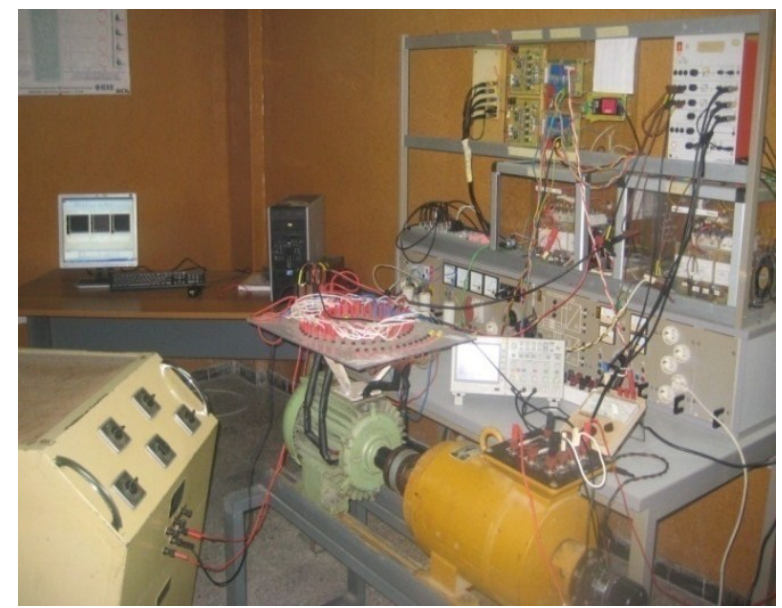

Fig. 8. Photography of the experimental test bench.

In order to verify the simulation results of the DPIG excitation control scheme (Fig. 2), experimental results are presented in this section. Figure 9 shows the generated voltage waveforms at no load with a magnitude corresponding to a reference value of $220 \mathrm{~V}$. They are balanced and their frequency is equal to $50 \mathrm{~Hz}$.

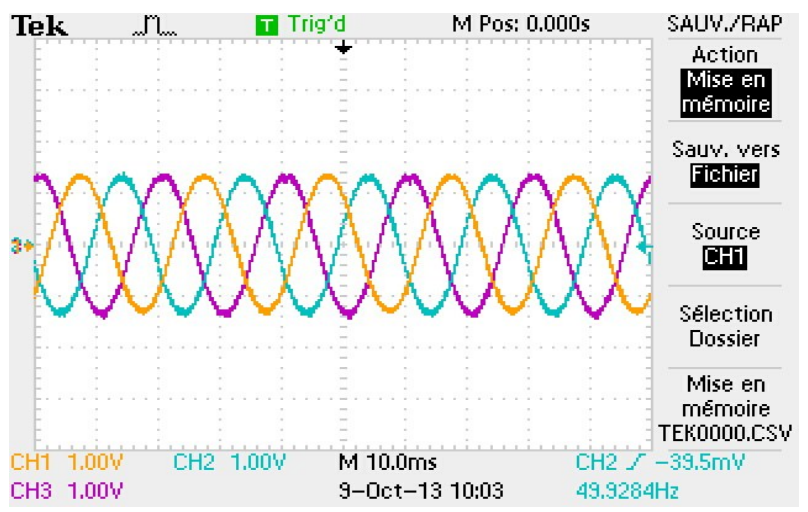

Fig. 9. Generated voltage waveforms at no load.

Figure 10 shows the voltage (yellow curve) and current (blue curve) waveforms with resistive load.

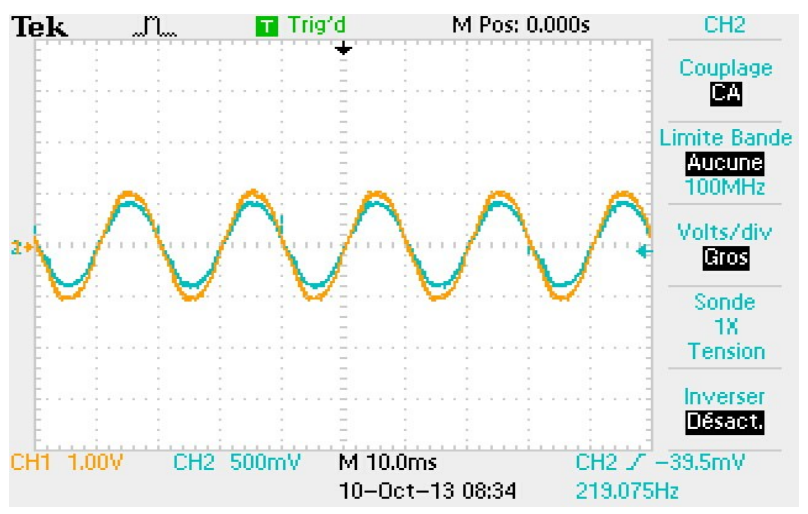

Fig. 10. Voltage and current waveforms with resistive load.

Figure 11 shows that the measured peak value of the PW phase voltage follows its reference before and after a speed variation using a simple PI regulator. 


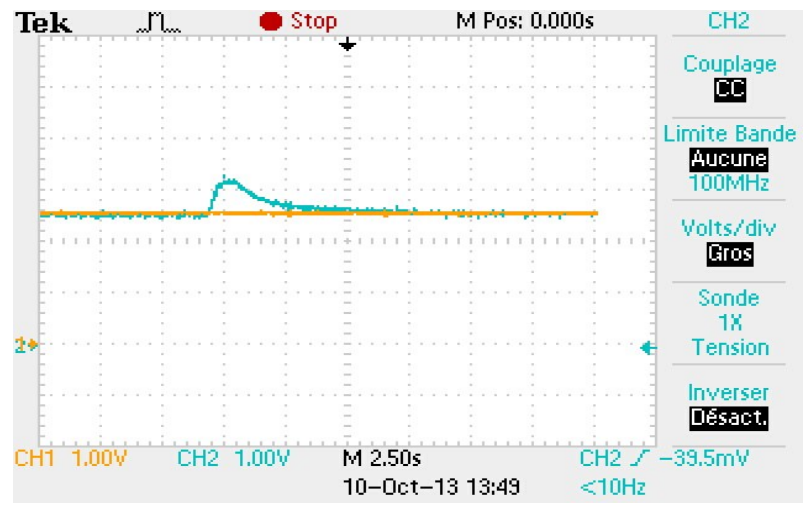

Fig. 11. The peak value of the measured PW phase voltage and its reference.

\section{Conclusion}

A dual star induction machine (DSIM), operating as an induction generator, supplying various loads under different conditions, is investigate by a series of simulation and experimental tests. Since, the DSIG has high number of phases, control strategies similar to that of doubly-fed induction generator can be developed and applied in order to adjust the generator output voltage and frequency. Thus, an operating mode based on an excitation control scheme of the DSIG is presented to ensure a controlled magnitude and frequency of the output voltage. So, the first star is connected to a PWM-VSI and used as excitation or control winding (CW) which provides the necessary reactive power, while the second one acts as power winding (PW) connected to the load and meets the active power demand. However, it is necessary to add a regulation loop of the excitation battery or capacitor voltage, which only can be maintained stable as long as the mechanical shaft input active power meets the load active power demand. Also, in order to make this kind of machines suitable for renewable energy applications, other control techniques can be developed.

\section{Appendix}

The constant coefficients of the magnetizing characteristics of SEIG are as follows:

$$
\begin{aligned}
& c_{1}=0.5312, c_{2}=1.1982, c_{3}=1.0618, \\
& c_{4}=2.0148, c_{5}=8.6710, c_{6}=1.1708 .
\end{aligned}
$$

\section{References}

[1] D. B. Watson, J. Amlaga, and T. Densem, "Controllable d.c. power supply from wind-driven self-excited induction machines," Proc. IEE, vol. 126, no. 12, pp. 1245-1248, 1979.

[2] J. B. Patton and D. Curtice, "Analysis of utility protection problems associated with small wind turbine interconnections," IEEE Trans. Power Apparatus and Systems, vol. 101, no. 10, pp. 3957-3966,1982.

[3] G. Raini and O.P. Malik, "Wind energy conversion using a self-excited induction generator," IEEE Trans. Power Apparatus and Systems, vol. 102, no. 1, pp. 3933-39362, 1983.

[4] F. Bu, Y. Hu, W. Huang, S. Zhuang and K. Shi, "Control Strategy and Dynamic Performance of Dual Stator-Winding Induction Generator Variable Frequency AC Generating System With Inductive and Capacitive Loads," IEEE Trans. Power Electron., vol. 29, no. 4, pp. 1681-1692, Apr. 2014.

[5] E.A. Klingshirn, "High phase order induction motors-Part I: Description and Theoretical consideration," IEEE Transactions on power Apparatus and Systems, Vol. 102, pp.47-53, 1983.

[6] K. Nounou, K. Marouani, M. Benbouzid and B. Tabbache, "Six-phase induction machine operating as a standalone self-excited induction generator," IEEE International Conference on Green Energy (IEEE-ICGE), Sfax, Tunisia pp. 158-163, March 2014.

[7] T. A. Lipo, "A dq model for six phase induction machines" Proc. ICEM'80, pp. 860-867, Sep.1980.

[8] P. Vas, "Sensorless vector and direct torque control," Ed. Oxford University Press, 1998.

[9] K. Marouani, "Contribution à la commande d'un entraînement électrique à base de moteur asynchrone double étoile," Phd. thesis (in french), Ecole Militaire Polytechnique, Algiers, Algeria, Jun. 2010.

[10] A. Nesba, "Caractérisation du phénomène de la saturation magnétique de la machine asynchrone," Phd. thesis (in french), Ecole Nationale Polytechnique, Algiers, Algeria, Jan. 2007.

[11] K. Natarajan, , A. M. Sharaf, , S. Sivakumar and S. Naganathan, "Modeling and control design for wind energy power conversion scheme using self-excited induction generator," IEEE Trans. Energ. Conv., , 1987, , vol. EC-2, no. 3, pp. 506-512, Sap. 1982.

[12] K. Marouani, H. Guendouz, B. Tabbache, F. Khoucha and A. Kheloui, "Experimental investigation of an emulator "Hardware In the Loop" for electric naval propulsion system," $21^{\text {st }}$ IEEE-Mediterranean Conference on Control and Automation (MED), Chania, Greece, 2013.

[13] O. Ojo, I.E. Davidson, "PWM-VSI inverter-assisted standalone dual stator winding induction generator," IEEE Trans. Industry Applications, vol.36, no.6, pp.1604-1611, Nov. /Dec. 2000. 